\title{
ESTABELECIMENTO E CAPACIDADE INFECTIVA DE GIGASPORA MARGARITA E GLOMUS CLARUM EM SOLO SOB EROSÃO ${ }^{1}$
}

\author{
Anselmo Lúcio dos Santos ${ }^{2}$ \\ Francisco Adriano De-Souza.4 \\ Ricardo Luiz Louro Berbara ${ }^{5}$ \\ José Guilherme Marinho Guerra ${ }^{3}$
}

Recebido em 13/01/1999. Aceito em 04/02/2000

\begin{abstract}
RESUMO - (Estabelecimento e capacidade infectiva de Gigaspora margarita Becker \& Hall e Glomus clarum Nicol. \& Gerd. em solo sob erosão). O processo de recuperação de áreas degradadas pode ser favorecido pela inoculação de plantas com fungos micorrízicos arbusculares (FMA), selecionados para efetividade e competitividade. Com o objetivo de avaliar o estabelecimento e a capacidade infectiva $(\mathrm{CI})$ de fungos introduzidos em relação à comunidade de fungos autóctones (FA), foram conduzidos dois experimentos em casa-de-vegetação. No primeiro, foram cultivadas 10 espécies de plantas (três gramíneas e sete leguminosas) com três tratamentos de inoculação [controle; G. margarita (CNPAB 001); G. clarum (CNPAB 005)]. No segundo, a Cl dos FMA foi avaliada no solo após o primeiro experimento, em bioensaio com plantas-iscas repicadas semanalmente para vasos contendo solo autoclavado. O estabelecimento e a $\mathrm{Cl}$ dos FMA foi baseada na presença de esporos após os cultivos. Os FMA introduzidos e as espécies vegetais influenciaram de modo diferenciado a esporulação dos FMA (Acaulospora rugosa, Entrophospora colombiana, Gigaspora margarita e Glomus macrocarpum). A inoculação possibilitou o estabelecimento dos fungos inoculados em todas as plantas avaliadas. No entanto, somente G. clarum apresentou $\mathrm{CI}$ frente a população de fungos autóctones. Foi constatado que a $\mathrm{CI}$ destes isolados não está relacionada com o número de esporos. A produção de inoculantes comerciais a partir destes fungos é discutida.
\end{abstract}

Palavras-chave - Glomales, endomicorriza, esporos, área degradada, inoculação, competitividade

\footnotetext{
ABSTRACT - (Establishment and infective capacity of Gigaspora margarita Becker \& Hall and Glomus clarum Nicol. \& Gerd. in eroded soil). The processes of recovering degraded lands may be benefited by the inoculation of selected arbuscular mycorrhizal fungi (AMF), for effectivety and competitiveness. Two greenhouse experiments were carried out, with the aim of evaluating the establishment and infective capacity (IC) of introduced fungi in relation to community of autochthonous fungi (AF). In the first study, 10 plant species were cultivated (three grasses and seven legumes) with three inoculum treatments [control; G. margarita (CNPAB 001); G. clarum (CNPAB 005)]. In the second study, the IC of the AMF was evaluated in the soil after the first experiment in bioassays, with

1 Parte da Dissertação de Mestrado do primeiro Autor. Trabalho apresentado no II Congresso Brasileiro de Micologia, Rio de Janeiro, RJ, 1998

2 Universidade Federal Rural do Rio de Janeiro, Seropédica, RJ

3 Embrapa Agrobiologia, C. Postal 74505, CEP 23851-970, Seropédica, Rio de Janeiro, Brasil

4 Autor correspondente e-mail: fdesouza@usa.net; endereço atual: Plant Research International, Binnenhaven 5, P.O.Box 16, 6700 AA Wageningen, The Netherlands

5 Departamento de Solos, Universidade Federal Rural do Rio de Janeiro, CEP 23851-970, Seropédica, RJ, Brasil
} 
trap plants transplanted weekly to pots containing autoclaved soil. The establishment and IC of AMF were based on the presence of spores after harvest. The introduction of AMF and the plant species influenced the sporulation of AF (Acaulospora rugosa, Entrophospora colombiana, Gigaspora margarita and Glomus macrocarpum) in a differentiated way. The inoculation made the establishment of the inoculated fungus in all tested plants possible. However, only G. clarum presented IC to compete with the autochthonous fungi. The IC of these isolates showed no relationship to number of spores. The production of commercial inoculum using these fungi is discussed.

Key words - Glomales, endomycorrhiza, spores, degraded land, inoculation, competitiveness

\section{Introdução}

A contribuição dos fungos micorrízicos arbusculares (FMA) para o crescimento de plantas já está bem caracterizada, principalmente quanto ao aumento da capacidade de absorção de nutrientes, em especial o fósforo (Smith \& Read 1997). Atualmente sabe-se que estes fungos são componentes importantes no processo de sucessão vegetal por contribuírem para a diversificação e a estabilidade de ecossistemas (van der Heijden et al. 1998), papel demonstrado em estudos conduzidos em áreas impactadas submetidas a processo de revegetação (Miller \& Jastrow 1992; De-Souza \& Silva 1996) e em ecossistemas naturais (van der Heijden et al. 1998).

O processo de degradação, em geral, remove o horizonte superficial do solo, camada rica em matéria orgânica, e que contém a maioria dos propágulos de organismos responsáveis pelo processo de revegetação natural. A baixa disponibilidade de recursos bióticos, aliada a condições físicas e químicas desfavoráveis ao crescimento de plantas, faz com que a recuperação destas áreas só se torne possível quando recursos (sementes, microrganismos, fertilizantes, etc.) são aplicados de modo a permitir a retomada do processo de sucessão vegetal (De-Souza \& Silva 1996).

Modelos tecnológicos, baseados no emprego de leguminosas arbóreas noduladas e micorrizadas, para revegetação de áreas degradadas vêm sendo utilizados com sucesso (Franco et al. 1994; Franco \& Faria 1997). Este sistema está fundamentado na simbiose tríplice leguminosa - bactéria diazotrófica - fungo micor- rízico, onde a associação da planta com estes dois microrganismos a torna apta a sobreviver em condições adversas. O caráter autotrófico da planta, associado à capacidade de fixar nitrogênio atmosférico da bactéria e a maior eficiência do micélio fúngico em absorver nutrientes e água, além de atuar na estruturação do solo, fazem desta tecnologia uma das melhores e mais econômicas maneiras de recuperar áreas impactadas (De-Souza \& Silva 1996; Franco \& Faria 1997). Um dos grandes impedimentos para o estabelecimento de plantas micotróficas em áreas degradadas, onde os FMA foram eliminados ou reduzidos, pode ser contornado através da inoculação destes fungos durante o preparo de mudas.

Com o intuito de selecionar fungos para a produção de inoculantes comerciais, são conduzidos testes de efetividade para a seleção de organismos promissores. Em seguida, os isolados selecionados são avaliados, sob condições próximas às naturais, quanto à capacidade de estabelecimento e competitividade, para que possam ser testados a campo e, posteriormente, recomendados para uso em larga escala.

Os fungos Gigaspora margarita Becker \& Hall (CNPAB 001) e Glomus clarum Nicol. \& Gerd.(CNPAB 005) vêm sendo empregados na produção de mudas de diversas espécies de leguminosas arbóreas, face aos benefícios que essas duas espécies proporcionam ao crescimento destas plantas (De-Souza não publicados). No entanto, pouco se conhece sobre a capacidade de estabelecimento e competitividade destes fungos após serem introduzidos em áreas impactadas. Este trabalho teve por objetivos avaliar o estabelecimento e a capacidade infec- 
tiva destes fungos, através da inoculação em gramíneas e leguminosas em um substrato natural, contendo a comunidade de fungos autóctones, oriundo da erosão de um solo Podzólico Vermelho.

\section{Material e métodos}

Localização e caracterização do local de coleta das amostras de solo - Em março/1997, foi coletada amostra de um solo Podzólico Vermelho (Brasil 1983), depositado por erosão em uma praça de sedimentos de um corte de estrada intensamente erodido, localizado no Município de Barra do Piraí, RJ. O solo apresentava textura argilosa e minerais primários, $\mathrm{pH}$ em água $(1: 2,5) 5,4$; matéria orgânica $0,14{\mathrm{~g} \cdot \mathrm{dm}^{-3} \mathrm{e}}^{-}$ nitrogênio $0,19 \mathrm{~g} . \mathrm{dm}^{-3}$; $\mathrm{Al}, \mathrm{Ca}$ e $\mathrm{Mg}$, respectivamente 1,8 e $12 \mathrm{mmol}_{\mathrm{c}} \cdot \mathrm{dm}^{-3}$ extraído por $\mathrm{KCl}$ $1 \mathrm{~N}$; e 12,8 e $48,1 \mathrm{mg} \cdot \mathrm{dm}^{-3}$, respectivamente, de P e K extraídos por Mehlich I (Embrapa 1979).

$\mathrm{Na}$ ocasião da coleta, a área apresentava vegetação esparsa composta por sapê (Imperata brasiliensis Trin) e capim gordura (Melinis minutiflora Pal. De Beauv.), e continha 466 esporos de FMA por $100 \mathrm{~cm}^{-3}$ de solo, entre os quais predominavam Acaulospora rugosa Morton, (238), seguida de Entrophospora colombiana Spain \& Schenck, (164), Glomus macrocarpum Tul. \& Tul., (46) e Gigaspora margarita, (18). Os esporos foram determinados após extração por peneiramento via úmida (Gerdemann \& Nicolson 1963), seguido de centrifugação em solução de sacarose a $45 \%$ (Daniels \& Skipper 1982), e contados sob microscópio estereoscópico após identificação. Para identificação, os esporos foram separados em microscópio estereoscópico, montados em lâminas e observados em microscópio óptico. Foram preparadas lâminas contendo esporos intactos e quebrados, em álcool polivínilo e lacto-glicerol (PVLG) e com solução de Melzer + PVLG 1:1. Para a identificação, foram utilizados o Manual de Shenck \& Pérez (1988) e outras referências pertinentes.
Experimento 1 - Avaliação do estabelecimento de $G$. margarita e $G$. clarum em solo erodido contendo a comunidade de fungos autóctones - O experimento foi conduzido em condições de casa-de-vegetação na Embrapa Agrobiologia, em solo nativo, oriundo do sítio de coleta e que continha a comunidade de FMA autóctone anteriormente relacionada. Foi utilizado o delineamento de blocos casualizados em arranjo fatorial, com 10 espécies de plantas, três tratamentos de inoculação de FMA e quatro repetições. As plantas utilizadas foram: braquiária (Brachiaria decumbens Stapf), milheto (Pennicetum glaucum L.), sorgo (Sorghum bicolor L.), amendoim-forrageiro (Arachis pintoi Krapovickas \& Gregory), crotalária (Crotalaria juncea L.), desmódio (Desmodium ovalifolium Wall), estilosantes (Stylosanthes guianensis Aubl.), kudzu tropical (Pueraria phaseoloides Benth \& Hook), mucuna-cinza (Mucuna pruriens Steph \& Bart) e soja perene (Neonotonia wrightii Lackey). Os tratamentos de inoculação de FMA foram: (1) controle não inoculado; (2) $100 \mathrm{~g}$ de inóculo de solo do acesso CNPAB 001 Gigaspora margarita e (3) $100 \mathrm{~g}$ de inóculo de solo de Glomus clarum, ambos inoculados a $5 \mathrm{~cm}$ da superfície do solo no momento do plantio.

Os inóculos dos FMA foram produzidos a partir de solo inóculo dos acessos CNPAB 001 Gigaspora margarita e CNPAB 005 Glomus clarum depositados no Banco de Germoplasma de Glomales da Embrapa Agrobiologia. Os acessos foram multiplicados, individualmente, em cubas plásticas contendo $20 \mathrm{~kg}$ de substrato, composto pela mistura de solo e areia na proporção de 1:1 (v:v) e tendo como planta hospedeira Brachiaria decumbens. Durante o período de crescimento, as plantas foram adubadas com solução nutritiva segundo Brundrett et al. (1994). Cinco meses após o plantio cessou-se a irrigação dos vasos, permitindo a secagem das plantas e do substrato. Posteriormente, o substrato foi retirado dos vasos, destorroado, peneirado e as raízes foram removidas, cortadas em fragmentos menores que um centímetro e novamente 
misturadas ao substrato. Os inóculos produzidos continham, $490 \mathrm{e} 4.300$ esporos por $100 \mathrm{~g}$ de solo, respectivamente, para Gigaspora margarita (CNPAB 001) e Glomus clarum (CNPAB 005), bem como hifas e raízes colonizadas.

$\mathrm{Na}$ preparação do experimento foram empregados vasos com $5 \mathrm{~kg}$ de solo não desinfestado. O solo do sítio de coleta foi seco, destorroado e passado em peneira com malha de $4 \mathrm{~mm}$ de abertura. Em seguida foi adubado com rocha fosfática de Araxá, na dose de $5,5 \mathrm{~g} \cdot \mathrm{kg}^{-1}$ de substrato (Manjunath et al. 1989). $\mathrm{O}$ fosfato apresentou $4 \%$ de $\mathrm{P}_{2} \mathrm{O}_{5}$ solúvel em ácido cítrico a $2 \%$, e $24 \%$ de $\mathrm{P}_{2} \mathrm{O}_{5}$ total. Aplicou-se também enxofre (S) sob a forma de $\mathrm{MgSO}_{4} \cdot 7 \mathrm{H}_{2} \mathrm{O}$ equivalente a $57,7 \mathrm{Kg} \cdot \mathrm{ha}^{-1}$, e micronutrientes (solução de Hoagland \& Arnon 1938). Nas gramíneas, foi aplicado o equivalente a $80 \mathrm{Kg} \cdot \mathrm{ha}^{-1}$ de $\mathrm{N}$, com a solução $1 \mathrm{M}$ de $\mathrm{NH}_{4} \mathrm{NO}_{3}$. As leguminosas foram inoculadas com Rhizobium específico ( $1 \mathrm{~mL}$.vaso ${ }^{-1}$ na forma líquida colocado sobre as sementes pré-germinadas) oriundo da coleção de culturas da Embrapa Agrobiologia. As sementes de soja perene, kudzu e estilosantes foram escarificadas com $\mathrm{H}_{2} \mathrm{SO}_{4}$ concentrado por cinco minutos. Com exceção da braquiária, que foi desinfestada com hipoclorito de sódio a $5 \%$, as sementes das outras espécies foram tratadas com $\mathrm{H}_{2} \mathrm{O}_{2}(30 \%)$ por três minutos. As sementes foram pré-germinadas em câmara de germinação a $25^{\circ} \mathrm{C}$ com umidade controlada até a emissão das radículas, sendo logo após transplantadas para os vasos definitivos e, aos 20 dias após a emergência (DAE), realizou-se o desbaste, permanecendo duas plantas por unidade experimental.

Após o cultivo das plantas, um período de 100 DAE, as raízes foram retiradas de forma a deixar somente esporos no solo. Em seguida, o substrato de cada vaso foi homogeneizado e utilizado para avaliar a capacidade infectiva (experimento 2). Em cada unidade experimental foram coletadas amostras de terra e de raízes, para quantificar a densidade de esporos e a colonização radicular. A extração dos esporos de
FMA foi realizada conforme descrito anteriormente. As amostras de raízes foram coletadas e armazenadas em etanol 50\% (Koske \& Gemma 1989). Na determinação da colonização micorrízica, as raízes foram clarificadas e coradas com azul-de-metila (Koske \& Gemma 1989). A avaliação da percentagem de colonizaçao foi realizada sob microscópio estereoscópico com aumento de 40x, pela técnica da intersecção de quadrantes (Giovannetti \& Mosse 1980).

Experimento 2 - Avaliação da capacidade infectiva (CI) dos fungos autóctones e introduzidos - Para determinar a CI dos fungos nos substratos provenientes do sítio de coleta e do experimento I, empregou-se a metodologia da planta isca, de acordo com Thomson et al. (1994), com modificações. Este bioensaio é conduzido em condições de casa-de-vegetação e é composto por duas fases. Na primeira fase, a planta isca é semeada em solo teste, onde fica exposta à colonização por períodos crescentes. Na segunda fase, as plantas são transferidas para vasos com solo livre de FMA, onde ocorre a esporulação dos fungos que colonizaram a planta na fase 1 , permitindo a identificação e a avaliação da CI.

$\mathrm{Na}$ fase I, sementes de sorgo BR $005 \mathrm{R}$ foram semeadas em substrato oriundo da amostra coletada à campo e das amostras provenientes dos tratamentos do experimento 1 . Na fase II, as plântulas de sorgo crescidas nestes substratos foram transplantadas para vasos contendo $1 \mathrm{~kg}$ de substrato autoclavado. Este substrato era oriundo do sítio de coleta, preparado conforme descrito anteriormente, sendo em seguida desinfestado (autoclavado duas vezes a $120^{\circ} \mathrm{Ce}$ pressão de $1,5 \mathrm{Kg} . \mathrm{cm}^{-3}$ durante uma hora, em dias alternados). As repicagens foram realizadas com intervalos de sete dias, a contar da data da emergência das plântulas, adotando-se seis épocas $(7,14,21,28,35$ e 42 dias após a emergência). Na repicagem, as plântulas foram cuidadosamente retiradas do substrato, lavadas com água destilada para retirar partículas de solo 
aderidas, e transplantadas para vasos. Cada vaso recebeu duas plântulas por tratamento. As plantas foram cultivadas até a produção de grãos, aproximadamente cinco meses, quando se coletaram amostras do substrato para a identificação das espécies de FMA. Na identificação e avaliação dos esporos de FMA foram adotados os mesmos critérios e técnicas já citados.

Análise estatística - Os dados foram submetidos a testes preliminares para verificar a normalidade e a homogeneidade de variância. No experimento I, a análise estatística das variáveis "densidade de esporos" e "comprimento de raiz colonizada" foi feita com os dados transformados, respectivamente para $\log (x+1)$ e arco seno $(\sqrt{x / 100})$, sendo analisados através da análise de variância, avaliando-se o efeito de cada fator isoladamente e da interação entre eles. Quando o teste F de Fischer-Snedecor foi significativo para a interação, a mesma foi desmembrada e o teste de Tukey $(\mathrm{p}<0,05)$ foi aplicado para comparar as médias entre os tratamentos.

\section{Resultados e discussão}

A comunidade de FMA autóctones, avaliada com base na ocorrência de esporos no solo, apresentou-se pouco diversificada e com distribuição que refletia o estádio de degradação da área. A população distribuiu-se segundo o modelo de abundância da série geométrica (DeSouza dados não publicados), que é típico de ecossistemas em estádios iniciais de sucessão ou comunidades perturbadas, onde ocorrem poucas espécies com grande diferença de abundância entre elas (Magurran 1988). As espécies encontradas são comuns em solos de regiões tropicais (Sieverding 1991) e a ocorrência destas tem sido reportada no Brasil. E. colombiana foi encontrada em solos sob cerrado (Miranda \& Miranda 1997) e G. macrocarpum é mais comum, tendo sido identificado em diversos ecossistemas (Trufem \& Viriato 1990; Trufem et al. 1990; Grandi \& Trufem 1991; De-Souza et al. 1999). Acaulospora rugosa Morton é sinônimo de A. longula Spain \& Schenck de $A$. morrowiae Spain \& Schenck (INVAM 1998), sendo também comum (Grandi \& Trufem 1991; Melo et al. 1997). Gigaspora margarita sinônimo G. ramisporophora (Bentivenga \& Morton 1995), a qual foi descrita a partir de solo coletado no Brasil (Spain et al. 1989) e também tem sido reportada com frequiência (Trufem et al. 1994; De-Souza et al. 1999).

A taxa de colonização radicular foi mais elevada em gramíneas e leguminosas anuais quando contrastadas com as perenes, com exceção da soja perene que apresentou resultados semelhantes aos da crotalária (Tab. 1). Nos tratamentos inoculados com G. clarum, a inoculação promoveu aumento na taxa de colonização radicular, em relação ao controle, para milheto, sorgo e crotalária, sendo estas as plantas que apresentaram as maiores taxas de colonização. A introdução de $G$. margarita seguiu a mesma tendência, porém de modo menos acentuado. Estes resultados indicam que os fungos introduzidos foram capazes de estimular a micorrização de algumas plantas no solo estudado. Esta afirmativa é reforçada pela correlação positiva obtida entre o acúmulo de fósforo na parte aérea das plantas testadas e o número de esporos de $G$. clarum encontrados após o cultivo destas plantas (Santos 1998).

Os dois fungos introduzidos foram capazes de estimular a taxa de colonização de algumas plantas, porém, as maiores respostas foram obtidas com a inoculação de $G$. clarum em relação a $G$. margarita. As variações na taxa de colonização entre as plantas inoculadas com estes fungos podem ser reflexo das diferenças na densidade de propágulos nos inóculos empregados, que foi maior para G. clarum, ou também, a capacidade infectiva destes fungos. A produção de inóculo para estas espécies é feita em vasos de cultivo a densidade de esporos obtidas para $G$. clarum é sempre superior à obtida para $G$. margarita (De-Souza dados não publicados). Técnicas mais eficientes de produção de inóculo têm sido propostas (Jarstfer \& Silvia 1995), no 
Tabela 1. Colonização radicular por FMA em gramíneas e leguminosas, inoculadas ou não com Gigaspora margarita ou Glomus clarum e cultivadas por 100 dias em substrato oriundo da erosão de um solo Podzólico Vermelho.

\begin{tabular}{|c|c|c|c|c|c|c|c|c|}
\hline \multirow{4}{*}{$\begin{array}{l}\text { Espécies vegetais } \\
\text { Braquiária }\end{array}$} & \multicolumn{8}{|c|}{ Tratamentos de Inoculação } \\
\hline & \multicolumn{2}{|c|}{ G. margarita } & \multicolumn{2}{|c|}{ G. clarum } & \multicolumn{2}{|c|}{ Controle } & \multicolumn{2}{|c|}{ Média geral } \\
\hline & \multicolumn{8}{|c|}{ Colonização radicular (\%) } \\
\hline & 40 & $\mathrm{BC}$ a & 41 & $\mathrm{CDE} \mathrm{a}$ & 30 & $\mathrm{ABCa}$ & 37 & $\mathrm{CD}$ \\
\hline Milheto & 63 & A & 75 & A a & 48 & A $\quad$ b & 62 & A \\
\hline Sorgo & 66 & A & 67 & $\mathrm{AB} \quad \mathrm{a}$ & 37 & $A B \quad b$ & 57 & $\mathrm{AB}$ \\
\hline Crotalária & 49 & $\mathrm{AB} \quad \mathrm{b}$ & 66 & $\mathrm{AB} \quad \mathrm{a}$ & 29 & BC $\mathrm{c}$ & 48 & $\mathrm{BC}$ \\
\hline Mucuna-cinza & 37 & $\mathrm{BCD} \mathrm{a}$ & 41 & $\mathrm{CD}$ a & 33 & $\mathrm{AB}$ a & 37 & $\mathrm{CD}$ \\
\hline Amendoim-forrageiro & 12 & E a & 12 & $\mathrm{~F} \quad \mathrm{a}$ & 10 & D $\quad \mathrm{a}$ & 11 & $\mathrm{~F}$ \\
\hline Desmódio & 24 & $\mathrm{DE} a$ & 24 & EF a & 21 & $\mathrm{BCD}$ a & 23 & $\mathrm{E}$ \\
\hline Estilosantes & 21 & $\mathrm{DE} a$ & 24 & DEF a & 16 & $C D$ a & 20 & $\mathrm{E}$ \\
\hline Kudzu tropical & 25 & $\mathrm{CD}$ a & 30 & CDE a & 26 & $\mathrm{BC}$ a & 27 & $\mathrm{DE}$ \\
\hline Soja perene & 34 & BCD a & 44 & BC a & 37 & $\mathrm{AB} \quad \mathrm{a}$ & 39 & $\mathrm{C}$ \\
\hline Média & 37 & b & 42 & a & 29 & c & & \\
\hline
\end{tabular}

Valores seguidos de mesma letra, minúsculas nas linhas e maiúsculas nas colunas, não diferem estatisticamente entre si pelo teste de Tukey a $5 \%$.

entanto o sistema de produção em vasos de cultivo ainda é o mais utilizado.

O efeito da inoculação sobre o crescimento e a produção de plantas pode refletir ação direta do fungo introduzido, ao colonizar as raízes da planta hospedeira, ou indireta, através de suas interações com as populações de fungos autóctones, tais como sinergismo, antagonismo e competição. A análise feita com base nos esporos obtidos por extração pode dar idéia da capacidade de estabelecimento de fungos (Fernandes \& Siqueira 1989), contudo, sabe-se que estes resultados nem sempre refletem a situação das populações de FMA no ecossistema. Isto se verifica, principalmente, nos casos onde o fungo não apresenta esporos no solo mas está colonizando a planta hospedeira (Clapp et al. 1995). O estabelecimento dos FMA está mais relacionado à capacidade competitiva e infectiva do que à produção de esporos (Gravina 1998).

A densidade de esporos totais, após o crescimento das plantas (Tab. 2), variou com o tratamento de inoculação e com a espécie de planta empregada. Ao comparar os efeitos dos tratamentos de inoculação com o número total de esporos após o cultivo das plantas (Tab. 2), verificou-se que os valores mais expressivos foram encontrados nos tratamentos onde foram in- troduzidos G. margarita e G. clarum. Com a introdução de G. margarita, o sorgo e o milheto foram as plantas que, em geral, promoveram os maiores aumentos no número total de esporos. Nos tratamentos com o G. clarum, as maiores densidades de esporos foram encontradas após o cultivo do milheto, do sorgo e da soja perene. Ao testar apenas as espécies autóctones, os resultados foram mais expressivos com o sorgo e o amendoim-forrageiro.

Dentre as plantas utilizadas neste estudo, a braquiária tem sido empregada na revegetação de taludes em rodovias e é muito empregada como planta hospedeira para multiplicação de FMA. De modo geral, a densidade de esporos após o cultivo desta gramínea perene foi similar ao das leguminosas avaliadas (Tab. 2). As gramíneas anuais sorgo e milheto apresentaram melhor desempenho. Neste estudo, estas espécies foram empregadas com finalidade comparativa, por serem espécies comprovadamente eficientes para a multiplicação de FMA (Simpson \& Daft 1990). As leguminosas forrageiras amendoim-forrageiro, desmódio, kudzu tropical e soja perene apresentam hábito de crescimento prostrado, assim como o estilosantes, e têm grande potencial para revegetação de encostas e para a recuperação 
Tabela 2. Número total de esporos de FMA em diferentes gramíneas e leguminosas, inoculadas ou não com Gigaspora margarita ou Glomus clarum e cultivadas por 100 dias em substrato oriundo da erosão de um solo Podzólico Vermelho.

\begin{tabular}{|c|c|c|c|c|c|c|c|c|c|c|c|}
\hline \multirow[b]{3}{*}{ Espécies vegetais } & \multicolumn{9}{|c|}{ Tratamentos de Inoculação } & \multirow{2}{*}{\multicolumn{2}{|c|}{ Média geral }} \\
\hline & \multicolumn{3}{|c|}{ G. margarita } & \multicolumn{3}{|c|}{ G. clarum } & \multicolumn{3}{|c|}{ Controle } & & \\
\hline & \multicolumn{9}{|c|}{ Número de esporos em $50 \mathrm{~cm}^{3}$ de solo } & & \\
\hline Braquiária & 300 & B & a & 142 & D & $\mathrm{b}$ & 127 & $\mathrm{C}$ & $\mathrm{b}$ & 189 & $\mathrm{BC}$ \\
\hline Milheto & 533 & A & a & 497 & A & $\mathrm{a}$ & 148 & $\mathrm{BC}$ & b & 393 & A \\
\hline Sorgo & 641 & A & $\mathrm{a}$ & -364 & $\mathrm{AB}$ & b & 270 & A & b & 425 & A \\
\hline Crotalária & 145 & D & $a b$ & 219 & $\mathrm{BCD}$ & $\mathrm{a}$ & 121 & $\mathrm{C}$ & $\mathrm{b}$ & 161 & $\mathrm{C}$ \\
\hline Mucuna-cinza & 281 & $\mathrm{BC}$ & a & 196 & $\mathrm{CD}$ & $\mathrm{a}$ & 200 & $\mathrm{ABC}$ & $\mathrm{a}$ & 225 & B \\
\hline Amendoim-forrageiro & 219 & $\mathrm{BCD}$ & $a b$ & 172 & $\mathrm{D}$ & $\mathrm{b}$ & 265 & A & a & 219 & $\mathrm{BC}$ \\
\hline Desmódio & 165 & $\mathrm{CD}$ & $\mathrm{a}$ & 170 & D & $\mathrm{a}$ & 137 & $\mathrm{BC}$ & a & 157 & C \\
\hline Estilosantes & 209 & $\mathrm{BCD}$ & a & 133 & D & $\mathrm{b}$ & 165 & $\mathrm{ABC}$ & $a b$ & 169 & $\mathrm{BC}$ \\
\hline Kudzu tropical & 163 & $\mathrm{CD}$ & a & 159 & D & $\mathrm{a}$ & 213 & $\mathrm{AB}$ & $\mathrm{a}$ & 178 & $\mathrm{BC}$ \\
\hline Soja perene & 205 & $\mathrm{BCD}$ & $a b$ & 293 & $\mathrm{ABC}$ & a & 173 & $\mathrm{ABC}$ & a & 224 & B \\
\hline Média & 286 & & $\mathrm{a}$ & 234 & & b & 182 & & c & & \\
\hline
\end{tabular}

Análise de variância feita a partir de dados transformados para log $(x+1)$.

Valores seguidos de mesma letra, minúsculas nas linhas e maiúsculas nas colunas, não diferem estatisticamente entre si pelo teste de Tukey a $5 \%$.

de pastagens degradadas. Essas espécies apresentaram bom desempenho principalmente quanto à multiplicação dos fungos autóctones (Tab. 2). As leguminosas anuais crotalária e mucuna-cinza são empregadas como adubos verdes e, juntamente com as gramíneas anuais, podem ser empregadas como culturas antecessoras de espécies micotróficas obrigatórias, visando o aumento da densidade de propágulos infectivos de FMA autóctones, conforme demostrado para batata-doce (Espindola et al. 1998) e mandioca (De-Souza et al. 1999).

Com base na densidade de esporos de cada espécie presente nas amostras de solo (Tab. 3), pode-se verificar que os dois fungos introduzidos foram capazes de se estabelecer, produzindo novos esporos. Como o tratamento controle apresentava um isolado de $G$. margarita indígena, a distinção entre ambos não foi possível através das técnicas empregadas neste trabalho. No entanto, a introdução da G. margarita promoveu aumento médio de $19 \%$ no número de esporos desta espécie em relação ao tratamento controle, o que evidencia o provável estabelecimento do fungo introduzido. Foi constatado que o sorgo foi a planta que mais estimulou a esporulação de G. margarita introduzido. Na comunidade indígena, foram o kudzu tropical e a mucuna-cinza, para os tratamentos G. clarum e controle, respectivamente. Estes resultados podem ser indicativos de diferenças entre os isolados de G. margarita introduzida e autóctone.

$\mathrm{O}$ isolado G. clarum também apresentou esporulação em todas as plantas avaliadas, sendo o milheto, o sorgo e a mucuna-cinza as que mais estimularam (Tab. 3). Quando comparado com a da G. margarita introduzida, a esporulação de $G$. clarum foi inferior, apresentado em média 39 esporos $100 . \mathrm{cm}^{-3}$ aos 100 obtidos para G. margarita.

A introdução dos fungos e as espécies de plantas utilizadas influenciaram de modo diferenciado a esporulação dos fungos autóctones. Este tipo de resposta é comum e foi relatado no Brasil por Balota \& Lopes (1996) em plantas de café inoculadas com G. margarita, e em sistemas de rotação com adubos verdes e mandioca, por De-Souza et al. (1999). De forma geral, Acaulospora rugosa apresentou as maiores densidades de esporos, sendo seguida por Entrophospora colombiana e por Glomus macrocarpum. A densidade de esporos obtida por G. margarita autóctone apresentou o mesmo patamar da produzida por Glomus 


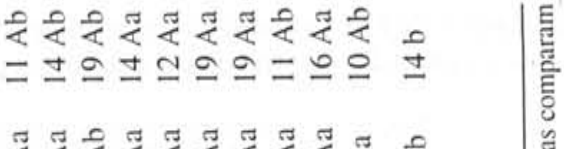

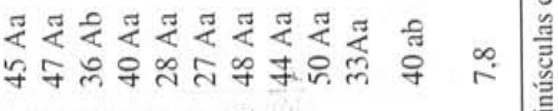

ઇ

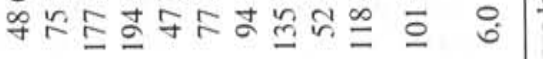

ยิ

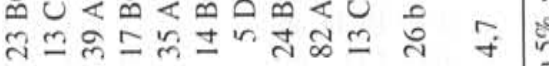

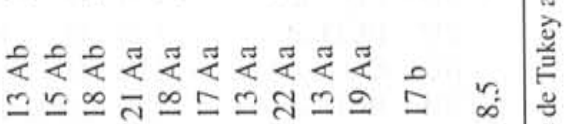

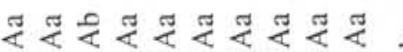

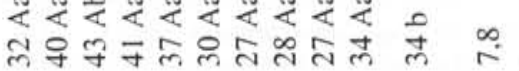

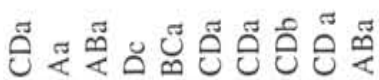

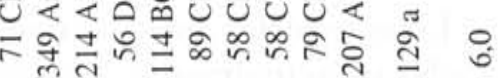

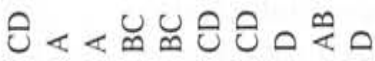

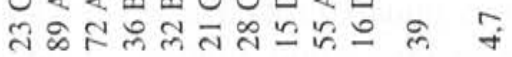

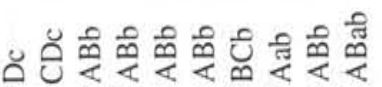

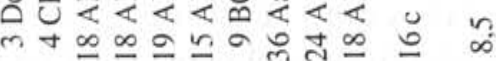

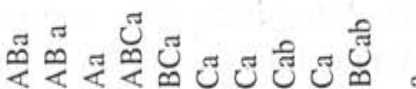

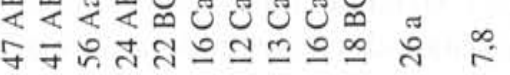

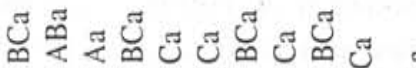

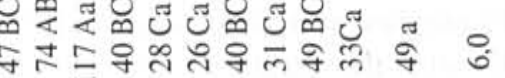

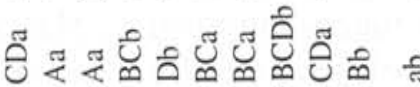

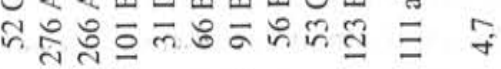

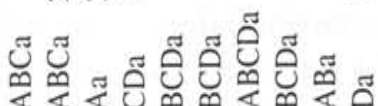

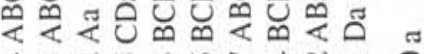

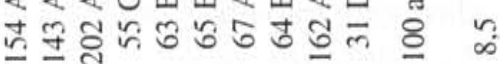

氖

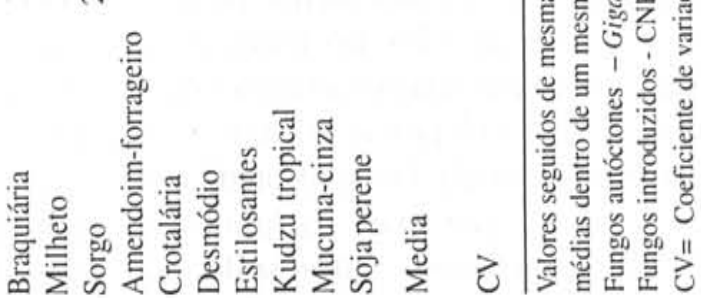




\section{macrocarpum.}

As plantas que mais favoreceram o aumento da densidade de esporos de A. rugosa, nos tratamentos inoculados, foram o milheto e o sorgo e, no controle, o sorgo e o amendoimforrageiro. A crotalária reduziu a densidade de esporos deste fungo nas fontes de inóculo de $G$. margarita e controle. Por outro lado, a introdução de G. clarum favoreceu a esporulação desta espécie quando associada ao milheto, soja perene e sorgo. Quanto a E. colombiana e $G$. macrocarpum, verificou-se que ocorreram variações entre plantas somente nos tratamentos inoculados com $G$. margarita, os quais favoreceram a esporulação destas espécies, principalmente quando associadas ao sorgo e ao milheto. Neste tratamento ocorreu redução na esporulação de A. rugosa e aumento das demais espécies, evidenciando efeito negativo da introdução da $G$. margarita sobre a esporulação de A. rugosa. O parâmetro densidade de esporos pode caracterizar a maior adaptabilidade da espécie às condições edafoclimáticas dominantes (Fernandes \& Siqueira 1989) e a compatibilidade com a planta hospedeira (Simpson \& Daft 1990).

A avaliação da capacidade infectiva do substrato oriundo diretamente do local de coleta revelou que os fungos autóctones $A$. rugosa, E. colombiana e G. macrocarpum apresentavam alta capacidade infectiva, sendo capazes de colonizar as plantas de sorgo já na primeira semana de exposição ao substrato (Tab. 4). Dentre os fungos autóctones, $G$. margarita não demonstrou capacidade infectiva até 42 dias de exposição no solo (Tab. 4). O substrato apresentava 18 esporos de $G$. margarita por $100 . \mathrm{cm}^{-3}$ e estes foram multiplicados após o experimento 1 , demonstrando a viabilidade dos esporos. Assim, conclui-se que esta espécie apresenta baixa capacidade infectiva quando comparada às demais espécies autóctones.

O bioensaio permitiu detectar a presença de mais uma espécie na comunidade, Acaulospora appendicula Spain, Sieverding \& Schenck, que infectou as plantas entre 22 e 28 dias de exposição ao solo teste (Tab. 4 e 5). Esta espécie não produziu esporos no experimento 1 , como também não foram detectados esporos no material original. No entanto, sabe-se que cultivos sucessivos ou mais prolongados favorecem a esporulação de número maior de espécies, especialmente as mais raras (Stutz \& Morton 1996). Há vários relatos de ocorrência de $A$. appendicula em ecossistemas brasileiros (Fernandes \& Siqueira 1989; Siqueira et al. 1989; Maia \& Trufem 1990; Barbosa \& Silva 1991; Trufem 1995), sendo considerada conespecífica à Acaulospora gerdemannii (Morton et al. 1997).

Tabela 4. Efeito do tempo de exposição (dias) sobre a colonização de FMA autoctónes de um solo erodido, proveniente do Municípo de Barra do Piraí, RJ, em plantas de sorgo.

\begin{tabular}{|c|c|c|c|c|c|c|}
\hline \multirow[t]{2}{*}{$\begin{array}{l}\text { Espécies de } \\
\text { FMAs observadas }\end{array}$} & \multicolumn{6}{|c|}{$\begin{array}{l}\text { Tempo de exposição para infecção da } \\
\text { planta teste em dias após a emergência }\end{array}$} \\
\hline & 7 & 14 & 21 & 28 & 35 & 42 \\
\hline A. appendicula & - & - & - & + & + & + \\
\hline A. rugosa & + & + & + & + & + & + \\
\hline E. colombiana & + & + & + & + & + & + \\
\hline G. margarita & - & - & - & - & - & - \\
\hline G. macrocarpum & + & + & + & + & + & + \\
\hline
\end{tabular}

(+) presença: (-) ausência de colonização

Os resultados do bioensaio para as amostras provenientes do experimento 1 (Tab. 5), no tratamento não inoculado, foram semelhantes aos obtidos para o solo antes do cultivo das plantas (Tab. 4), com exceção da A. appendicula. Esta espécie apresentou maior capacidade infectiva, ocorrendo após o cultivo de 3, 8 e 10 plantas a partir, respectivamente, da segunda, terceira e quinta semana de exposição ao solo. A detecção de $G$. margarita ocorreu somente no tratamento resultante do cultivo de estilosantes, inoculado com essa espécie, a qual foi observada de forma esparsa entre o $15^{\circ}$ e o $35^{\circ}$ dia de exposição. Por outro lado, G. clarum foi detectado em sete das 10 plantas já na primeira semana do bioensaio, e a partir da segunda semana estava 
Tabela 5. Efeito do tempo de exposição (dias) sobre a colonização de FMA introduzidos (Gigaspora margarita e Glomus clarum) e autóctones, em plantas de sorgo cultivadas em solo erodido, após o cultivo com diferentes espécies de gramíneas e leguminosas por um período de 100 dias.

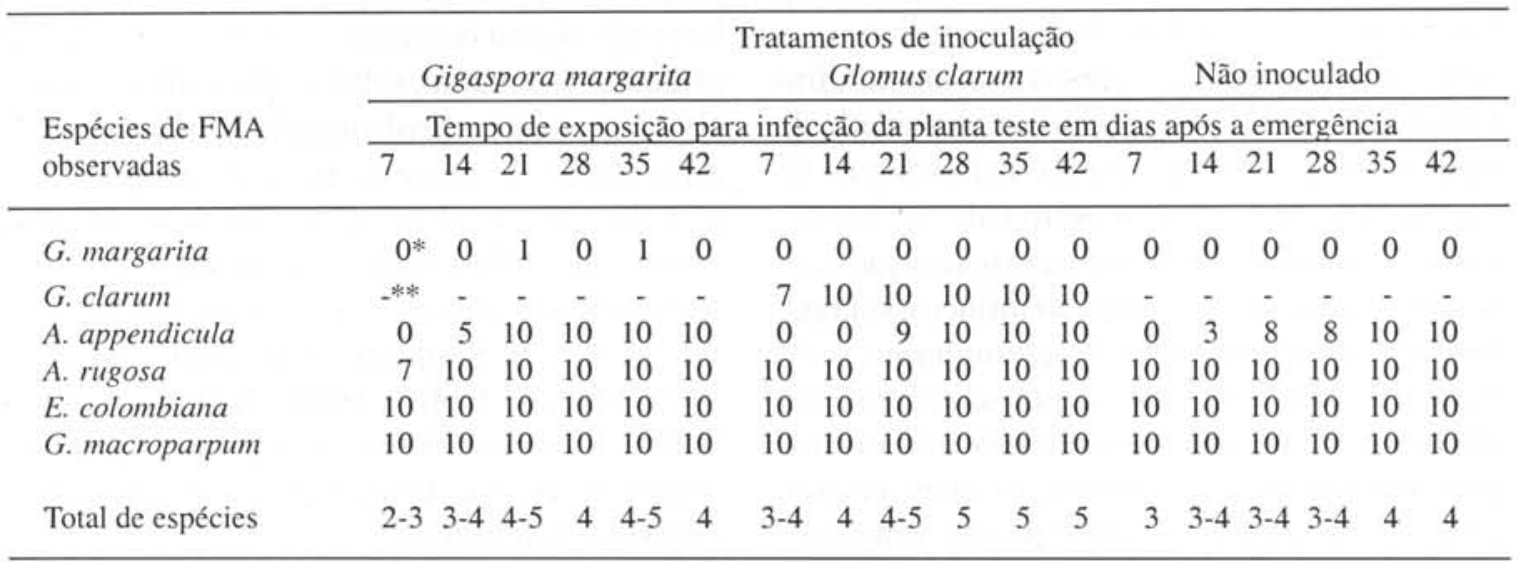

* números de 0 a 10 representam o número de espécies de plantas onde a presença do fungo foi positiva.

** (-) não inoculado

presente em $100 \%$ das plantas, em todas as demais épocas avaliadas, demonstrando alta capacidade infectiva em relação a $G$. margarita (Tab. 5). As espécies autóctones E. colombiana e G. macrocarpum foram as mais infectivas, estando presentes em todos os tratamentos e épocas avaliadas (Tab. 4 e 5). A. rugosa apresentou o mesmo padrão que estas espécies no substrato antes e após os cultivos, nos tratamentos controle e inoculado com G. clarum. A inoculação de $G$. margarita reduziu a capacidade infectiva da $A$. rugosa após o cultivo do sorgo, milheto e da soja perene. Estes resultados confirmam o efeito deletério da inoculação da G. margarita sobre A. rugosa após o cultivo do sorgo e do milheto (Tab. 3 e 5) e demonstram que a capacidade infectiva desta espécie não esta ligada à densidade de esporos na amostra, visto que a maior densidade de esporos de $A$. rugosa foi obtida após o cultivo do sorgo e do milheto inoculado com G. margarita (Tab. 3). Por outro lado, a inoculação de G. margarita aumentou a capacidade infectiva da $A$. appendicula em relação aos demais tratamentos de inoculação (Tab. 5) e a amostra inicial (Tab. 4). Nos tratamentos onde G. clarum foi inoculado, a capacidade infectiva de $A$. appendicula foi menor, evidenciando possível efeito negativo da introdução de $G$. clarum sobre esta espécie.

$\mathrm{O}$ conhecimento das interações positivas e negativas entre macro e microssimbiontes pode contribuir para a introdução e/ou manejo direcionado da população de fungos em agroecossistemas, de forma a estimular populações de espécies mais efetivas para plantas de interesse econômico e reduzir aquelas pouco eficientes (Sieverding 1991; De-Souza et al. 1999). Neste sentido, o isolamento e a avaliação da efetividade de populações de FMA autóctones para culturas-alvo é fundamental, bem como o desenvolvimento e a validação de métodos para estudo da ecologia de Glomales. Neste sentido, o emprego do bioensaio da capacidade infectiva permitiu avaliar o comportamento dos FMA introduzidos e autóctones. Este trabalhoé o primeiro a empregar esta técnica para avaliar o estabelecimento de fungos introduzidos. $\mathrm{O}$ bioensaio da capacidade infectiva é uma técnica simples e fornece resultados que permitem avaliar o comportamento e a interação entre espécies de FMA, facilitando ainda o isolamento e a identificação de fungos, pois funciona como planta-armadilha, permitindo a obtenção de 
grande número de esporos.

A análise conjunta dos dois experimentos evidenciou que a densidade de propágulos não tem relação com a capacidade infectiva. Apesar da diferença de densidade de propágulos entre os inóculos de G. margarita e G. clarum utilizados, G. margarita apresentou maior densidade de esporos após o cultivo das plantas testadas (Tab. 3) do que G. clarum. Sabe-se que esporos de $G$. margarita germinam entre dois a quatro dias e produzem grande quantidade de micélio (Paula \& Siqueira 1990), enquanto os esporos de G. clarum levam mais tempo para germinar (De-Souza \& Berbara 1999) e produzem menor quantidade de micélio (Paula et al. 1994). No entanto, a capacidade infectiva da G. margarita foi muito baixa em relação à de $G$. clarum, que obteve resultado semelhante ao das espécies autóctones mais infectivas em $70 \%$ das plantas testadas, após a primeira semana, e em $100 \%$, após a segunda.

A inoculação localizada favorece a introdução de organismos selecionados. No entanto, se o organismo introduzido não apresentar competitividade frente aos organismos autóctones, pode desaparecer em pouco tempo, necessitando ser reintroduzido, o que pode ser inviável técnica e economicamente. Para a condição avaliada, o isolado de G. margarita não apresentou boa capacidade infectiva, o que pode restringir os benefícios na planta inoculada e contribuir para o desaparecimento deste fungo após algumas gerações.

O isolado de $G$. clarum apresentou alta capacidade infectiva e pode competir com a comunidade de fungos autóctones, que apresentava número total de esporos por vaso 5,4 vezes maior do que a quantidade inoculada. Para o solo estudado, que é dominante no Estado do Rio de Janeiro, os resultados obtidos justificam o emprego do isolado G. clarum (CNPAB 005) na produção de inoculantes comerciais, visando a inoculação de plantas que sejam beneficiadas por este fungo.

\section{Agradecimentos}

À Embrapa Agrobiologia pelo auxílio financeiro (SEP n. 01.0.96.032 e 11.0.96.041) e pela permissão de uso de suas instalações; à CAPES e ao CNPq, pela concessão de bolsas de estudo, respectivamente, ao primeiro, o segundo e o terceiro autores. Ao técnico Itamar Garcia Ignácio, pela produção dos inoculantes de FMA empregados neste estudo.

\section{Referências bibliográficas}

Bentivenga, S. P. \& Morton, J. B. 1995. A monograph of the genus Gigaspora, incorporating developmental patterns of morphological characters. Mycologia 87: 719-731.

Balota, E. L. \& Lopes, E. S. 1996. Introdução de fungo micorrízico arbuscular no cafeeiro em condições de campo: I. Persistência e interação com espécies nativas. Revista Brasileira de Ciência do Solo 20: 217-223.

Barbosa, L. M. \& Silva, M. R. O. 1991. Estudos qualiquantitativos da ocorrência de fungos micorrízicos vesículo-arbusculares (MVA) na cultura do amendoinzeiro (Arachis hypogaea L.) sob matocompetição. Hoehnea 18: 189-200.

Brasil. 1983. Geografia, geomorfologia, pedologia, vegetação e uso potencial da terra. Pp. 780. Projeto RADAM Brasil. Ministério das Minas e Energia. Secretaria Geral. Folha SF 23/24. Rio de Janeiro/ Vitória, Rio de Janeiro.

Brundrett, M.; Melville, L. \& Peterson, L. 1994. Isolating and propagating glomalean fungi. $\mathrm{Pp}$. 71 80. In: Pratical methods in mycorrhiza research. Mycologue Publications, Guelph, Canada.

Clapp, J. P.; Young, J. P. W.; Merryweather, J. W. \& Fitter, A. H. 1995. Diversity of fungal symbionts in arbuscular mycorrhizas from a natural community. New Phytologist 130: 259-265.

Daniels, B. A. \& Skipper, H. D. 1982. Methods for the recovery and quantitative estimation of propagules from soil. Pp.29-35. In: N. C. Schenck (Ed.), Methods and principles of mycorrhizal research. American Phytopathological Society, St. Louis.

De-Souza, F. A. \& Berbara, R. L. L. 1999. Ontogeny of Glomus clarum in Ri T-DNA transformed roots. Mycologia 91: 343-350. 
De-Souza, F. A. \& Silva, E. M. R. 1996. Micorrizas arbusculares na revegetação de áreas degradadas. Pp. 255-290. In: J. O. Siqueira (Ed.), Avanços em fundamentos e aplicação de micorrizas. Universidade Federal de Lavras, DCS/DCF, Lavras.

De-Souza, F. A.; Trufem, S. F. B.; Almeida, D. L.; Silva, E. M. R. \& Guerra, J. G. M. (1999). Efeito de pré-cultivos sobre o potencial de inóculo de fungos micorrízicos arbusculares e produção da mandioca. Pesquisa Agropecuária Brasileira 34: 1913-1923.

EMBRAPA. 1979. Manual de métodos de análise de solo. Serviço Nacional de Levantamento e Conservação de Solos. SNLCS, Rio de Janeiro.

Espíndola, J. A. A.; Almeida, D. L.; Guerra, J. G. M.; Silva, E. M. R. \& De-Souza, F. A. 1998. Influência da adubação verde sobre a simbiose micorrízica e a produção de batata-doce. Pesquisa Agropecuária Brasileira 33: 339-347.

Fernandes, A. B. \& Siqueira, J. O. 1989. Micorrizas vesículo-arbusculares em cafeeiros da Região Sul do Estado de Minas Gerais. Pesquisa Agropecuária Brasileira 24: 1489-1498.

Franco, A. A.; Campello, E. F. C.; Dias, L. E. \& Faria, S. M. 1994. Revegetation of acidic residues from bauxita mining using nodulated and mycorrhizal legume trees. Pp. 313-320. In: Proceedings nitrogen fixing trees for acid soil. Turrialba, Costa Rica.

Franco, A. A. \& Faria, S. M. 1997. The contribution of $\mathrm{N}_{2}$-fixing tree legumes to land reclamation and sustainability in the tropics. Soil Biology and Biochemistry 29: 897-903.

Gerdemann, J. W. \& Nicolson, T. H. 1963. Spores of mycorrhizal Endogone species extracted from soil by wet-sieving and decanting. Transactions of the British Mycological Society 46: 235-244.

Giovannetti, M. \& Mosse, B. 1980. An evaluation of techniques for measuring vesicular arbuscular mycorrhizal infection in roots. New Phytologist 84 : 489-500.

Grandi, R. A. P. \& Trufem, S. F. B. 1991. Fungos micorrízicos vesículo-arbusculares em Marantaceae cultivadas no Instituto de Botânica, São Paulo, SP. Revista Brasileira de Botânica 14: 89-95.

Gravina, G. A. 1998. Densidade de propágulos infectivos e capacidade infectiva de fungos micorrízicos arbusculares (FMA), em solo sob leguminosas herbáceas perenes. Dissertação de Mestrado. Universidade Federal Rural do Rio de Janeiro, Seropédica.

Hoagland, D. R. \& Arnon, D. I. 1938. The water culture method of growing plants without soil. Circular $\mathbf{n}$. 347. Agricultural Experimental Station, California.
INVAM 1998. International Culture Collection of Vesicular and Arbuscular Mycorrhizal Fungi. Species Description. Morgantown, West Virginia Agriculture and Forestry Experimental Station. Home Page. [http: \invam.caf.wvu.edu]

Jarstfer, A. G. \& Sylvia, D. M. 1995. Aeroponic culture of VAM fungi. Pp. 427-441. In: A. Varma; B. Hock (Eds.), Mycorrhiza: structure, function, molecular biology and biotechnology. SpringerVerlag, Berlin.

Koske, R. E. \& Gemma, J. N. 1989. A modified procedure for staining roots to detect VA mycorrhizas. Mycological Research 92: 488-505.

Magurran, A. E. 1988. Ecological diversity and its measurement. Princenton University Press, Princenton. New Jersey.

Maia, L. C. \& Trufem, S. F. B. 1990. Fungos micorrízicos vesículo-arbusculares em solos cultivados no Estado de Pernambuco, Brasil. Revista Brasileira de Botânica 13: 89-95.

Manjunath, A.; Hue, N. V. \& Habte, M. 1989. Response of Leucaena leucocephala to vesicular-arbuscular mycorrhizal colonization and rock phosphate fertilization in an oxisol. Plant and Soil 114: 127-133.

Miller, R. M. \& Jastrow, J. D. 1992. The application of VA mycorrhizae to ecosystem restoration and reclamation. Pp. 438-467. In: M. A. Allen (Ed.), Mycorrhizal functioning, an integrative plantfungal process. Chapman \& Hall, New York.

Miranda, J. C. C. \& Miranda, L. N. 1997. Micorriza arbuscular. Pp. 67-111. In: M. A., Vargas \& M., Hungria (Eds.), Biologia dos solos dos cerrados. Embrapa - CPAC, Planaltina.

Melo, A. M. Y.; Maia, L. C. \& Morgado, L. B. 1997. Fungos micorrízicos arbusculares em bananeiras cultivadas no vale do submédio São Francisco. Acta Botanica Brasilica 11: 115-121.

Morton, J. B.; Bever, J. D. \& Pfleger, F. L. 1997. Taxonomy of Acaulospora gerdemannii and Glomus leptotichum, synanamorphs of an arbuscular mycorrhizal fungus in Glomales. Mycological Research 101: 625-631.

Paula, M. A. \& Siqueira, J. O. 1990. Stimulation of hyphal growth of the VA mycorrhizal fungus Gigaspora margarita suspension-cultured Pueraria phaseoloides cells and cell products. New Phytologist 115: 69-75.

Paula, M. A.; Siqueira, J. O. \& Döbereiner, J. 1994. Crescimento micelial de fungos micorrízicos vesículo-arbusculares na presença de células vegetais e de bactérias diazotróficas in vitro. Revista Brasileira de Biologia 54: 631-639. 
Santos, A. L. 1998. Estabelecimento de Gigaspora margarita e Glomus clarum por gramíneas e leguminosas e esporulação de fungos micorrízicos arbusculares indígenas. Dissertação de Mes-trado.Universidade Federal Rural do Rio de Janeiro, Seropédica.

Schenck, N. C. \& Pérez, Y. 1988. Manual for the identification of VA mycorrhizal fungi. 2.ed. INVAM, Plant Pathology Department. Gainesville, Florida.

Sieverding, E. 1991. Vesicular-arbuscular mycorrhiza management in tropical agrosystems. Eschborn, Friedland Bremer.

Simpson, D. \& Daft, M. J. 1990. Spore production and mycorrhizal development in various tropical crop host infected with Glomus clarum. Plant and Soil 121: 171-178.

Siqueira, J. O.; Colozzi-Filho, A. \& Oliveira, E. 1989. Ocorrência de micorrízas vesículo-arbusculares em agro e ecossistemas do Estado de Minas Gerais. Pesquisa Agropecuária Brasileira 24: 1499-1506.

Smith, S. E. \& Read, D. J. 1997. Mycorrhizal symbiosis. Academic Press, San Diego.

Spain, J. L.; Sieverding, E. \& Schenck, N. C. 1989. Gigaspora ramisporophora: a new species with novel sporophores from Brazil. Mycotaxon 34: 667677.

Stutz, J. C. \& Morton, J. B. 1996. Successive pot cultures reveal high species richness of arbuscular endomycorrhizal fungi in arid ecosystems. Canadian Journal of Botany 74: 1883-1889.
Thonson, T. E.; Manian, S. \& Udaiyan, K. 1994. The effect of vesicular-arbuscular mycorrhizal exposure period on their colonization and spore production in tomato seedlings (Lycopersicon esculentum Mill.), and on host biomass. Agriculture, Ecosystems and Environment 51: 287-292.

Trufem, S. F. B. 1995. Aspectos ecológicos de fungos micorrízicos arbusculares na rizosfera de plantas de restinga da Ilha do Cardoso, SP, Brasil. Revista Brasileira de Botânica 18(1): 51-60.

Trufem, S. F. B.; Malatinszky, S. M. M. \& Otomo, H. S. 1994. Fungos micorrízicos arbusculares em rizosferas de plantas no litoral arenoso do Parque Estadual da Ilha do Cardoso, SP, Brasil. 2. 1994. Acta Botanica Brasilica 8: 219-229.

Trufem, S. F. B. \& Viriato, A. 1990. Fungos micorrízicos vesículo-arbusculares da Reserva Biológica do Alto da Serra de Paranapiacaba, São Paulo, Brasil. Revista Brasileira de Botânica 13: 49-54.

Trufem, S. F. B.; Grandi, R. A. P. \& Silveira, R. B. A.1990. Fungos micorrízicos vesículo-arbusculares em plantas ornamentais do Jardim Botânico de São Paulo, SP. Hoehnea 17: 85-89.

van der Heijden, M. G. A.; Boller, T.; Wiemken, A. \& Sanders, I. R. 1998. Different arbuscular mycorrhizal fungal species are potential determinants of plant community structure. Ecology 79(6): 2082-2091. 